\title{
CELAS E SALAS: A RECENTE PRODUÇÃO ACADÊMICA SOBRE EDUCAÇÃO ESCOLAR NA PRISÃO (2003-2017)
}

CELLS AND ROOMS: THE RECENT ACADEMIC PRODUCTION ON SCHOOL EDUCATION IN PRISON (2003-2017)

CELAS Y SALAS: LA RECIENTE PRODUCCIÓN ACADÉMICA SOBRE EDUCACIÓN ESCOLAR EN LA PRISIÓN (20032017)

ARAGÃO, Ariane Martins ${ }^{1}$

ZILIANI, Rosemeire de Lourdes Monteiro²

\begin{abstract}
RESUMO
O texto apresenta resultados de pesquisa bibliográfica que teve como objetivo analisar a produção sobre educação escolar nas prisões, no cenário brasileiro. Como metodologia foram mapeadas produções acadêmicas (teses e dissertações) disponíveis nas plataformas da BDTD-IBICT e da CAPES. Dos 258 trabalhos localizados foram selecionados somente 12 para análise, considerando o objetivo da pesquisa. Evidencia-se que apesar de garantias legais a educação escolar no sistema prisional é problemática, ainda que parte dos sujeitos acreditem em seu papel ressocializador. Conclui-se que o tema permanece como objeto a ser pensado e problematizado na atualidade.
\end{abstract}

Palavras-chave: Estado do conhecimento. Escolarização. Ressocialização.

\section{ABSTRACT}

The text presents results of bibliographical research that had as objective to analyze the production on school education in prisons, in the Brazilian scenario. As a methodology, academic productions (theses and dissertations) were mapped on the BDTD-IBICT and CAPES platforms. Of the 258 localized studies, only 12 were selected for analysis, considering the research objective. It is evidenced that, despite legal guarantees, school education in the prison system is problematic, although some of the subjects believe in their resocializing role. It concludes that the theme remains an object to be thought and problematized in the present time.

Keywords: State of knowledge. Schooling. Resocialization.

\section{RESUMEN}

El texto presenta resultados de investigación bibliográfica que tuvo como objetivo analizar la producción sobre educación escolar en las cárceles, el escenario brasileño. Como metodología se asignaron producciones académicas (tesis y disertaciones) disponibles en las plataformas de BDTD-IBICT y de CAPES. De los 258 trabajos localizados fueron seleccionados solamente 12 para análisis, considerando el objetivo de la investigación. Se evidencia que a pesar de garantías legales la educación escolar en el sistema penitenciario es problemática, aunque parte de los sujetos creen en su papel resocializador. Se concluye que el tema permanece como objeto a ser pensado y problemático en la actualidad.

Palabras clave: Estado del conocimiento. Escolarización. Resocialización.

\footnotetext{
1 Universidade Federal da Grande Dourados - UFGD - Dourados - Mato Grosso do Sul - Brasil

2 Universidade Federal da Grande Dourados - UFGD - Dourados - Mato Grosso do Sul - Brasil
} 


\section{INTRODUÇÃO}

Levando-se em conta a pertinência social e acadêmica do tema no contexto brasileiro e a obrigatoriedade da oferta de educação escolar aos indivíduos em privação de liberdade, este escrito apresenta resultados de pesquisa sobre educação prisional ou educação escolar na prisão presente em produções acadêmicas (teses e dissertações) disponíveis na plataforma da Biblioteca Digital de Teses e Dissertações (BDTD), do Instituto Brasileiro de Informação em Ciência e Tecnologia (IBICT)3 e da Coordenação de Aperfeiçoamento de Pessoal do Ensino Superior (CAPES). Trata-se de pesquisa bibliográfica, realizada entre 2017 e 2018, cujo objetivo foi o de cartografar o conhecimento sobre o tema "educação escolar na prisão". Não foi estabelecido um recorte temporal nas buscas, entretanto levando-se em conta os trabalhos selecionados o período foi definido entre 2003 e 2017.

Nas buscas foram usados os descritores "educação and penitenciária and modelo panóptico" (descritor 1), "educação and unidades prisionais and modelo panóptico" (descritor 2) e "educação and prisões" (descritor 3). Com esses descritores foram localizados 258 trabalhos, sendo selecionados apenas 12, que se constituiu na amostra para análise, considerando o objeto de interesse da pesquisa: a educação escolar na prisão.

Trata-se de um estado parcial do conhecimento, utilizando os trabalhos completos que compõem o mapa da produção privilegiado, considerando que alguns dos resumos não contavam com as informações necessárias ou possuem limites sobre sua utilização como principal fonte (FERREIRA, 2002).

Para divulgar os resultados o texto foi dividido em mais duas partes, sendo a primeira uma reflexão sobre aspectos teóricos pinçados como centrais sobre a temática e a segunda traz os resultados do mapa construído a partir da pesquisa bibliográfica.

\section{A RELEVÂNCIA SOCIAL E CIENTÍFICA DO TEMA}

A Educação escolar no Brasil é considerada um direito social, garantido na Constituição Federal (BRASIL, 1988), não podendo ou devendo ser vista como algum tipo de privilégio. Nessa perspectiva, a Educação de Jovens e Adultos (EJA), é um "programa social" que surgiu da necessidade de possibilitar a conclusão do Ensino Fundamental e do Ensino Médio para pessoas que por algum motivo não terminaram esses níveis de escolaridade em idade considerada "apropriada". 0 programa serve como estímulo para que jovens e adultos voltem à escola, respeitando as peculiaridades de cada pessoa e procurando se adequar a sua condição de vida, para que o aluno não interrompa a "nova" oportunidade.

\footnotetext{
${ }^{3}$ IBICT é uma instituição que coordena a BDTD e integra as informações sobre teses e dissertações de instituições de ensino e pesquisa do Brasil. http://bdtd.ibict.br/vufind/Institutions.
} 
Considerado instância produtiva, o espaço-tempo escolar ocupa, desde a segunda metade do século passado, parte significativa da vida de crianças, adolescentes e jovens no país e, em certa medida, os compõem e conformam como subjetividades (ROSE, 2001) escolarizadas, mas também não escolarizadas, pois os que a ela não têm acesso tomam para si essa "falta" e nela organizam seus "eus", estereotipando-se como analfabetos, não qualificados e outros qualificativos, justificando assim parte das desigualdades instauradas em nossa sociedade.

Segundo Zanetti e Catelli Jr. (2014, p. 19-20):

[...] a educação aparece como direito social marcada por uma enorme demanda, dadas as trajetórias de vida dos que hoje fazem parte da população carcerária brasileira. Pesquisar a educação em prisões torna-se fundamental, na medida em que a compreensão de suas especificidades pode colaborar para que se atenda de maneira efetiva ao direito dos encarcerados à educação ao longo da vida.

A maioria da população carcerária não concluiu os estudos (BRASIL/INFOPEN, 2016), e esse é um dos motivos usados para justificar a necessidade de oferecer a educação escolar no interior das prisões. No Brasil, jovens e adultos que estão em situação de privação de liberdade estão incluídos nesse direito à educação e para cumprir tal obrigatoriedade constitucional, as secretarias estaduais de educação passam a oferecer o programa nas penitenciárias, por meio de intervenções para oferecer Ensino Fundamental e Ensino Médio, na modalidade EJA.

Seguindo esse mesmo princípio, a Lei de Diretrizes e Bases da Educação Nacional (LDB), de 20 de dezembro de 1996 (BRASIL, 1996) ratifica este direito e considera que o acesso ao Ensino Fundamental é um direito público subjetivo, ou seja, o Poder Público pode ser acionado juridicamente para que as pessoas tenham este direito garantido. A Lei de Execução Penal (LEP), Lei $n^{\circ} 7.210$, de 11 de julho de 1984 (BRASIL, 1984), entre outros documentos oficiais, situam a educação como um direito de todos, independentemente de estarem ou não privados de liberdade.

A educação nos presídios está inserida na modalidade EJA, porém seus objetivos e especificidades vão muito além dessa proposta, oferecida para pessoas que não estão em situação de privação de liberdade. Segundo registros da história da educação nos presídios brasileiros essa educação existe desde a década de 1960 e em quase todas as unidades da Federação, porém sua institucionalização nos presídios acontece depois de sua regulamentação, quando as aulas dadas por monitores presos passam a ser ministradas por professores das Redes Estaduais de Educação (REEs) e as Secretarias de Administração Penitenciária (SAPs) passam a dividir atribuições com essas redes.

A prisão é um espaço-tempo pensado em primeiro lugar pela preocupação com a segurança e somente secundariamente com outros aspectos, entre eles o educacional. No espaço-tempo prisional a educação escolar, quando presencial, com as salas e sua arquitetura própria, constitui-se como um "outro lugar" no espaço-tempo de privação de liberdade. Entretanto, podemos supor que funciona como uma heterotopia (FOUCAULT, 2001), lugar real, mas de passagem, assim como se espera que seja a própria prisão. Espaços heterogêneos, que inscrevem-se em construções culturais e históricas 
datadas, como o modelo de aprisionamento e seu correlato sistema de punição, estudado por Foucault (1987).

Para Foucault (1987, p. 224), “a educação do detento é, por parte do poder público, ao mesmo tempo uma preocupação indispensável no interesse da sociedade e uma obrigação para com o detento". O poder público oferece educação escolar na prisão como um "direito", legalmente garantido, mas lembremos que no Brasil não existe prisão perpétua (CONSTITUIÇÃO FEDERAL, 1988); nesses termos, em algum momento, o sujeito preso "voltará" a sociedade e, para "garantia" de que ele não perturbará a organização e a paz públicas, propugna-se sua ressocialização, sendo a escola/escolarização considerada ferramenta útil para atingir esse fim. Porém, para o detento ela não é uma obrigação, mas é "incentivada" ou "conduzida" pela redução da pena, conforme a Lei de Execução Penal (LEP), Lei nº 7.210, de 11 de julho de 1984 (BRASIL, 1984).

A Lei $n^{\circ}$ 12.433, de 29 de junho de 2011 (BRASIL, 2011, s/p, grifo do original) que alterou a LEP, define que:

Art. 126. O condenado que cumpre a pena em regime fechado ou semiaberto poderá remir, por trabalho ou por estudo, parte do tempo de execução da pena.

$\S 1^{\circ} \mathrm{A}$ contagem de tempo referida no caput será feita à razão de:

I - 1 (um) dia de pena a cada 12 (doze) horas de frequência escolar - atividade de ensino fundamental, médio, inclusive profissionalizante, ou superior, ou ainda de requalificação profissional - divididas, no mínimo, em 3 (três) dias.

Refletindo sobre esse aspecto, podemos nos indagar não somente sobre o espaço-tempo da prisão, mas da escola em seu interior. Como conceber uma organização em que aspectos que parecem se opor, como segurança e educação escolar coexistam? Parece-nos possível utilizar a concepção de heterotopia para pensar essa "coexistência", levando-se em conta, entre outros aspectos, o fato de a escola como construção sociocultural, instaurar-se na geografia da prisão e se tornar espaço-tempo específico na vida dos internos. Lembremos que essa "opção" dirigida aos sujeitos aprisionados possui seus próprios limites e condições, como o comportamento dos internos, que delimita quem e quantos podem usufruir dessa possibilidade na prisão.

Ainda, conforme aponta Freire (2001, p. 97-98):

\begin{abstract}
A educação não é a chave, a alavanca, o instrumento para a transformação social. Ela não o é, precisamente porque poderia ser. E é exatamente essa contradição que explicita, que ilumina, que desvela a eficácia limitada da educação. O que quero dizer é que a educação é limitada, a educação sofre limites.
\end{abstract}

A oferta de educação nas prisões tem se organizado de forma "precária". Em parte significativa das Secretarias de Administração Penitenciária (SAPs) não há um setor para organizar a assistência educacional, afetando a dinâmica e qualidade do atendimento. A Relatoria Nacional para o Direito 
Humano à Educação (BRASIL, 2009, p. 3), aponta que o atendimento educacional nas unidades prisionais:

[...] quando existente, em sua maior parte sofre de graves problemas de qualidade apresentando jornadas reduzidas, falta de projeto pedagógico, materiais e infraestrutura inadequados e falta de profissionais de educação capazes de responder às necessidades educacionais dos encarcerados.

Estudos sobre a reincidência criminal apontam que suas expectativas acabam, na maioria das vezes, frustradas pelos rótulos, pelo despreparo em assumir atividades profissionais, por distorções de visão de mundo que fatalmente adquirem no que Julião (2009 apud ONOFRE; JULIÃO, 2013, p. 3) denominam "sociedade dos cativos".

Para Abreu (2016, s/p):

\begin{abstract}
O cárcere é um 'espaço geograficamente repleto de contradições'. É um lugar em que vivem pessoas de diferentes idades, classes sociais e que estão pagando a pena por ter cometido os mais variados "crimes", desde pequenos furtos até homicídios ou estupros. Ao mesmo tempo em que possui homens e mulheres que praticaram atos definidos como "erros" ou delitos e estão privadas de liberdade, há também os que cometeram e continuam praticando crimes dentro e fora da prisão, seja contra um cidadão extramuros, um servidor prisional ou outro detento. Além disso a oferta de educação escolar, não se constitui tarefa simples, como não o é fora das prisões; um dos aspectos são os espaços destinados para a escolarização e também pela escassez de profissionais capacitados e interessados em trabalhar em um presídio.
\end{abstract}

De acordo com Luna (1985 apud MIRABETE; FABBRINI, 2007, p. 25), "A finalidade das penas privativas de liberdade, quando aplicadas, é 'ressocializar', recuperar, reeducar ou educar o condenado, tendo uma finalidade educativa que é de natureza jurídica”.

Zanetti e Catelli Jr. (2014, p. 31) evidenciam, entre outros aspectos, o funcionamento de uma "lógica da reclusão e não da ressocialização" presente nas penitenciárias e um baixo índice tanto de oferta quanto de participação dos aprisionados em atividades educacionais.

Como explicitado, nem todos os presos tem ou terão acesso à educação escolar na prisão. De acordo com a Relatoria Nacional para o Direito Humano à Educação (BRASIL, 2009, p. 3), as vagas disponibilizadas são inferiores:

[..] à demanda pelo acesso à educação, geralmente atingindo de $10 \%$ a $20 \%$ da população encarcerada nas unidades pesquisadas. As visitas às unidades e os depoimentos coletados apontam a existência de listas de espera 3 extensas e de um grande interesse pelo acesso à educação por parte das pessoas encarceradas.

Ainda de acordo com a Relatoria (BRASIL, 2009, p. 2), a permanência na escola é usada como "moeda de troca" entre os agentes, gestores e presos, neste ponto a educação fica entendida como privilégio dentro de um sistema penitenciário, envolta em um jogo de interesses e poderes. 
Coyle (2002) enfatiza que os presos são seres humanos e, por isso, os servidores penitenciários não devem perder de vista este fundamental conceito. Não podem impor penas cruéis e muito menos, punições adicionais às pessoas presas, tratando-as como se fossem seres irracionais, que não possuem o mínimo de dignidade e perderam o direito de serem respeitados. Afirma ainda que as atividades educacionais nos presídios não devem ser apenas consideradas como regalia concedida pela administração penitenciária. Ela vem sendo colocada nos discursos contemporâneos como um elemento central na recuperação do indivíduo, capaz de oferecer oportunidades para um melhor aproveitamento do tempo em que cumpre a sentença na prisão. Mas é preciso lembrar que a prisão, entre outras instituições sociais modernas, estudadas por Foucault (1987, p. 114), é um espaço-tempo no qual as tecnologias disciplinares e de controle funcionam, e que possui como finalidade "[...] fixar os indivíduos em um aparelho de normalização do homem”. Assim, essas instituições, tornam-se capazes de colaborar para a produção de "novas" redes de poder-saber que favorecem a atualização das possibilidades de fabricação do sujeito moderno.

Destaca-se que a noção de resistência se constitui elemento inerente às relações de poder. Segundo Foucault (2006), o próprio poder é efeito de um conjunto de práticas, de relações de forças, agindo umas sobre as outras, sem estar localizado ou totalizado em um indivíduo ou em uma instância como o Estado. Do mesmo modo que o exercício de poder, as forças de resistência, não têm poder absoluto. Sabe-se que a prisão e a escola como instituições disciplinadoras/controladoras também apresentam imposições e brechas, determinações e possibilidades, relações de poder e forças de resistência, coexistindo em um processo dialético e pulsante. 


\section{A PRODUÇÃO CIENTÍFICA DISPONÍVEL NA CAPES E NA BDTD-IBICT}

Para as buscas das produções disponíveis nos bancos de dados eleitos para a pesquisa foram utilizados três descritores, conforme apresentado no Quadro 1.

Quadro 1. Localização e seleção dos trabalhos nas plataformas CAPES e BDTD-IBICT

\begin{tabular}{|l|l|c|c|c|c|}
\hline \multirow{2}{*}{\multicolumn{2}{c|}{ Descritores }} & \multicolumn{3}{c|}{ Plataformas } \\
\cline { 3 - 6 } \multicolumn{2}{c|}{} & \multicolumn{2}{|c|}{ CAPES } & \multicolumn{2}{c|}{ BDTD-IBICT } \\
\cline { 3 - 7 } & $\begin{array}{c}\text { Trabalh } \\
\text { os } \\
\text { localiza } \\
\text { dos }\end{array}$ & $\begin{array}{c}\text { Após a } \\
\text { seleção }\end{array}$ & $\begin{array}{c}\text { Antes da } \\
\text { seleção }\end{array}$ & $\begin{array}{c}\text { Após a } \\
\text { seleção }\end{array}$ & \\
\hline D1 & Educação AND penitenciária AND & 16 & 3 & 1 & 0 \\
\hline D2 & $\begin{array}{l}\text { Educação AND unidades prisionais } \\
\text { AND modelo panóptico }\end{array}$ & 4 & 0 & 1 & 0 \\
\hline D3 & Educação AND prisões & 146 & 7 & 90 & 2 \\
\hline Total & & 166 & 10 & 92 & 2 \\
\hline
\end{tabular}

Fonte: Dados de pesquisa (2017-2018).

No total foram localizados 258 trabalhos, dos quais apenas 12 foram selecionados, considerando o objetivo da pesquisa ora socializada, que se centrou na educação escolar nos espaços-tempos prisionais, levantando questões como a oferta, funcionamento, organização e espaçotempo. Para tanto levaram-se em conta os títulos e resumos dos trabalhos.

A seguir foram identificados os trabalhos selecionados, incluindo ano, instituição e os temas estudados. No portal Capes, em relação ao Descritor 2, não foi selecionado nenhum trabalho. Em relação ao primeiro descritor, "educação and penitenciária and modelo panóptico", foram selecionados 2 trabalhos (Quadro 2): 
Quadro 2. Identificação dos trabalhos na plataforma CAPES (Descritor 1)

\begin{tabular}{|l|l|l|r|c|}
\hline N. & Ano & Tipo & Instituição & Tema \\
\hline 1 & 2017 & Mestrado & $\begin{array}{r}\text { Universidade Estadual do } \\
\text { Oeste do Paraná }\end{array}$ & $\begin{array}{c}\text { Direitos } \\
\text { humanos/ressocialização }\end{array}$ \\
\hline 2 & 2017 & Mestrado & $\begin{array}{r}\text { Universidade Estadual da } \\
\text { Bahia }\end{array}$ & $\begin{array}{r}\text { Projeto Político Pedagógico e } \\
\text { educação prisional }\end{array}$ \\
\hline 3 & 2010 & Mestrado & $\begin{array}{r}\text { Centro Universitário Salesiano } \\
\text { de São Paulo }\end{array}$ & Educação e ressocialização \\
\hline
\end{tabular}

Fonte: Dados da pesquisa bibliográfica (2017-2018).

Ainda na plataforma CAPES, para o descritor 3, "educação and prisões", foram selecionados sete trabalhos (Quadro 3).

Quadro 3. Identificação dos trabalhos na plataforma CAPES (Descritor 3)

\begin{tabular}{|l|l|l|l|l|}
\hline N & Ano & Tipo & Instituição & Tema \\
\hline 1 & 2017 & Mestrado & Universidade Tuiuti do Paraná & Educação prisional e políticas \\
públicas
\end{tabular}




\begin{tabular}{|l|l|l|l|l|}
\hline 7 & 2003 & Mestrado & $\begin{array}{c}\text { Pontifícia Universidade } \\
\text { Católica do Rio de Janeiro }\end{array}$ & $\begin{array}{c}\text { Políticas } \\
\text { públicas/ressocialização }\end{array}$ \\
\hline
\end{tabular}

Fonte: Dados da pesquisa bibliográfica (2017-2018).

Na plataforma da BDTD-IBICT foram selecionados 2 trabalhos, presentes somente no terceiro descritor, "educação and prisões", conforme exposto no Quadro 4.

Quadro 4. Identificação dos trabalhos na plataforma BDTD-IBICT (Descritor 3)

\begin{tabular}{|l|l|l|l|l|}
\hline N. & Ano & Tipo & Instituição & Tema \\
\hline 1 & 2011 & Mestrado & $\begin{array}{c}\text { Pontifícia Universidade } \\
\text { Católica de Goiás }\end{array}$ & Educação/ressocialização \\
\hline 2 & 2011 & Mestrado & $\begin{array}{l}\text { Universidade Federal da } \\
\text { Paraíba }\end{array}$ & Educação/ressocialização \\
\hline
\end{tabular}

Fonte: Dados da pesquisa bibliográfica (2017-2018).

Os trabalhos selecionados referem-se a diferentes temas e abordagens da educação em sistemas prisionais. O período de conclusão dos trabalhos selecionados foi de 2003 a 2017, portanto uma produção recente, com pouco mais de uma década. Utilizando os descritores apresentados, os trabalhos selecionados foram majoritariamente realizados em nível de mestrado, com apenas uma tese, que aborda os "espaços-tempos da escola na prisão".

Os trabalhos foram realizados em universidades de vários estados brasileiros, evidenciando tanto o interesse quanto a problemática da educação nas prisões brasileiras.

\section{OS DITOS E ESCRITOS NAS PRODUÇÕES SOBRE EDUCAÇÃO NA PRISÃO}

Zanetti e Catelli Jr. (2014) realizaram levantamento no banco de teses e dissertações da CAPES, sobre o tema "educação em prisões", no período entre 2000 e 2012 tornando-se referência em pesquisas sobre o conhecimento produzido acerca da temática. Na pesquisa aqui socializada privilegiamos o período entre 2003 e 2017, ampliando o período do levantamento das produções acadêmicas sobre o tema, mas com diferentes descritores, como exposto na parte anterior.

No mapa traçado encontramos pesquisas que refletem sobre o papel da educação no ambiente escolar, para pensar seus limites e possibilidades, a ressocialização, as políticas públicas, a docência, 
entre outros aspectos mais específicos de algumas penitenciárias brasileiras. Observamos a relevância dada em alguns trabalhos a perspectiva dos sujeitos presos e dos professores que atuam em prisões.

Refletindo e fazendo a critica ao papel da escola na prisão, como possibilidade de modificar os comportamentos, ressocializar os aprisionados, localizamos os trabalhos de Santos (2017), Franca (2016), Gomes (2013), Silva (2011), Silva Junior (2011), Sorge (2010) e Julião (2003).

Silva (2011, p. 163) explicita que

[...] a prisão, longe de defender a sociedade ensinando aos prisioneiros os valores coletivamente aceitos e preparando-os para o retorno ao convívio, atua como um instrumento de expiação das emoções coletivas na busca por um equilíbrio de forças entre a violência do crime e a violência do Estado. Acredita-se, portanto, que quanto mais a prisão infligir sofrimento ao prisioneiro, mas perfeita será a vingança contra a criminalidade, e assim, a sensação de segurança pública se mantém dentro de padrões aceitáveis.

Indagando sobre o que pode a educação na prisão, o autor investiga suas possibilidades e limites nesta instituição social. Identifica, ao final, que a educação escolar desenvolvida no contexto do cárcere é permeada por várias barreiras, no entanto, o preso vislumbra um conjunto de "novas possibilidades", uma realidade diferente, alheia ao mundo do crime.

Franca (2016) investigou o que pensam os sujeitos que se encontram em situação de privação de liberdade, sobre os "possíveis" efeitos da educação em suas vidas, tomando as representações sociais como objeto de atenção. Os resultados revelam que os sujeitos constroem uma representação social sobre a educação, concebendo-a em um papel redentor e guia para ação de "novos comportamentos":

\footnotetext{
De acordo com as expectativas debositadas no processo educativo intramuros. a atividade escolar node cheaar an imacinário dos internos relacionada com o selı nrenarn nara o retorno social. Assim. encontramos bontos que se entrelacam na essência dessas instituicões. bois enquanto a escola se apresenta como espaco de formacão ética. indicando o resneito aos preceitos humanos da plena cidadania individual e coletiva. o presídio. para além do seu banel nunitivo node se transformar em ambiente aue node contribuir para a formação do homem no seu retorno ao convívio social. (FRANCA, 2016, p. 95).
}

O trabalho de Silva Jr. (2011) busca compreender o papel da educação no ambiente prisional, nas perspectivas educativa e jurídica. Explicita o papel atribuído a prisão na vida do indivíduo preso e problematiza a questão do "retorno" do mesmo à sociedade:

Pensava-se que somente a detenção proporcionaria transformação aos indivíduos enclausurados. A ideia era que os condenados pudessem refazer seus objetivos de vida dentro da prisão, uma espécie de autoanálise. A disciplina do silêncio e da meditação nas sagradas escrituras iriam auxiliar esse pensamento. Assim, depois disso, eles estariam prontos para retornarem à sociedade. Entretanto, percebeu-se o fracasso desse objetivo. Os índices de criminalidade e reincidência dos crimes não diminuíram e os presos, em sua maioria, não se transformavam. A prisão mostrou-se em sua realidade e em seus efeitos como o "grande fracasso da justiça penal. (SILVA JÚNIOR, 2011, p. 99).

Sorge (2010) realiza uma pesquisa em três unidades prisionais, em contato direto com 
detentos e funcionários da Secretaria de Administração Penitenciária, para compreender como ocorre o processo educacional de detentos e elenca muitas falhas no modelo educacional observado. Segundo aponta, para que a "meta de ressocialização" seja alcançada, devem haver mudanças na educação dos detentos. O autor trabalha com a hipótese que a educação pode ressocializar além de diminuir as taxas de reincidência criminal, e aponta um modelo:

\begin{abstract}
Em síntese, a proposta de educação que se intenciona para detentos prevê a adoção do Centro de Ressocialização como unidade básica do sistema prisional, com um acesso mais ampliado, impedindo somente o ingresso de membros de facção criminosa e de detentos que tenham cometido faltas graves. Nessa unidade, a proposta prevê que educação e trabalho estejam conectados, com o detento iniciando o cumprimento de sua pena, fazendo um curso técnico e complementando seus estudos regulares, para após trabalhar nesta área durante o cumprimento de sua pena, tendo por fim auxilio ao reconquistar a liberdade, para se empregar e, quem sabe, abandonar de vez a vida do crime. Com essa proposta, tem-se a convicção que a reincidência seria diminuída, o que é de interesse de toda a sociedade, já que a democracia consiste em dar oportunidades iguais a todos, mesmo àqueles que erram. (SORGE, 2010, p.100).
\end{abstract}

Refletindo sobre o papel da escola no sistema penitenciário do Rio de Janeiro, que já possui 30 anos, a pesquisa de Julião (2003) descreve e analisa a relação entre educação escolar e ressocialização. O texto propõe uma análise da versão oficial da política de educação desenvolvida nos presídios e aponta a visão que alunos e professores têm a respeito da política educacional. Problematizando a sociedade e não somente a prisão afirma que

[...] a escola nos presídios tem uma enorme responsabilidade na formação de indivíduos autônomos, na ampliação do acesso aos bens culturais em geral, no fortalecimento da autoestima desses sujeitos assim como na consciência de seus deveres e direitos, criando oportunidades para o seu reingresso na sociedade. Ciente de que o problema das cadeias está fora de seus muros, visto que a camada da sociedade que se encontra enclausurada é, e sempre foi, a excluída de direitos sociais e dos bens de produção, acredito que a educação, livre da ideia assistencialista empregada modernamente, tanto se justifica como parcela possível da solução para os que já se encontram lá dentro, como para os que vivem excluídos socialmente, sendo eventuais candidatos para vida carcerária. (JULIÃO, 2003, p. 105).

Santos (2017) levanta o entendimento de alunos e professores sobre a educação escolar como oportunidade de "reabilitação social" para o preso. O trabalho enfatiza que isoladamente a educação não é capaz de resolver os problemas que são inerentes ao sistema prisional. E que, apesar de a Lei de Execução Penal (LEP), de 1984, assegurar educação e trabalho ao privado de liberdade, considerando-os o "método" mais eficaz para o processo de ressocialização, o sistema penitenciário brasileiro, assim como em outros países, não está alcançando o objetivo propugnado, a "ressocialização", visto que os índices de reincidência são considerados altos. Os resultados da pesquisa apontam a importância do trabalho conjunto entre Estado e sociedade na luta pela garantia de educação plena nas prisões, capaz de emancipar e reinserir o preso dignamente na sociedade. Em suas análises aponta que o sistema penitenciário é um "reflexo" da sociedade capitalista, que exclui todos aqueles que fogem do padrão construído historicamente e/ou que, de alguma forma, ameaçam a propriedade privada, razão de ser do sistema econômico vigente no Brasil. Para Santos (2017, p. 150): 
I- Seria interessante que a sociedade de uma forma geral entendesse que a educação escolar ofertada aos presos não é 'esmola', nem benevolência do Estado, é direito humano garantido por leis nacionais e internacionais das quais o Brasil é signatário;

II- A insatisfação com a criminalidade é unânime. Seria importante que essa unanimidade também existisse sobre a verdade de que o grande vilão dessa história é o sistema imposto, que escolhe a vítima, criminaliza o pobre e depois o pune, simples assim.

Realizado em uma penitenciária feminina do Rio de Janeiro, Gomes (2013) compreende o processo de escolarização como fortalecimento da autonomia do sujeito, no sentido de empoderamento, de maneira que a aprendizagem resulte em um fortalecimento de si mesmo. A autora utilizou fontes orais, por meio de memórias escolares escritas pelas presas e algumas atividades expressivas da escola, como os murais produzidos por elas no ano de 2012:

Refletir acerca do que ocorre com o interior do sujeito no universo das instituições totais é exercitar-se em prol de estudos que não vejam estas instituições como meros depósitos de internados, como se não tivessem mais solução, mas sim como um local onde existem pessoas com possibilidades de mudança. Para isso é necessário, primeiramente, saber se existe a possibilidade de organização de um conjunto de políticas, voltadas a atividades que coloquem estas pessoas que estão no sistema prisional, em condições de entender a gravidade do delito que cometeram. Caso contrário, de que serve a passagem pela prisão? Não pode constituir-se num tempo perdido, vazio. (GOMES, 2013, p. 178).

Sobre a necessidade de políticas para a educação prisional, com indicações de possíveis caminhos ou alternativas ressaltamos os trabalhos de Barreto (2017), Vidolin (2017) e Lourenço (2005).

Um dos aspectos levantado por Barreto (2017), refere-se a construção de um Projeto Político Pedagógico (PPP) específico, no qual a Educação de Jovens e Adultos (EJA) em prisões seja capaz de trazer reflexões, debates, discussões e compromisso com o aluno preso. Enfatiza o respeito as diversidades e particularidades do público alvo da educação escolar na prisão. A pesquisa ocorreu no Colégio Professor George Fragoso Modesto, localizado no Complexo Penitenciário da Mata Escura, em Salvador, onde a autora trabalha. Sobre o PPP afirma que:

[...] pode/deve ser dispositivo que favoreça a construção de conceitos, considerando o contexto sociocultural dos estudantes em condições de privação de liberdade. Entretanto, vale ressaltar que a inconsistência dos PPP analisados tem comprometido o fortalecimento da educação nesse espaço. Essas inconsistências se tornam mais evidentes em relação à EJA no sentido de que as propostas pedagógicas ainda não estão alinhadas às condições que vivem esses estudantes. (BARRETO, 2017, p. 121)

Vidolin (2017) afirma a necessidade de consolidação da educação no sistema prisional, que passa pela urgência do reconhecimento da dignidade do sujeito, pelo respeito aos direitos adquiridos pelos detentos de exercer a cidadania e pela falta de efetivação de políticas públicas que garantam o desenvolvimento da EJA no sistema prisional brasileiro.

A autora analisou a legislação e a implementação da educação no cárcere e concluiu que a 
necessidade de consolidação da educação neste ambiente é emergencial:

[...] a escola pode cumprir dois importantes papéis, dependendo da forma como é encarada: pode servir como um claro mecanismo de adequação dos indivíduos, introjetando neles valores e regras sugeridos pela instituição prisional ou, até mesmo, levar em consideração as visões sociais a respeito de como deve ser um condenado; ou pode, por meio de uma concepção educacional libertadora, viabilizar que a pessoa privada de liberdade liberte-se das amarras que a prendem a uma condição de exclusão social. (VIDOLIN, 2017, p. 101).

Vidolin (2017, p. 106) afirma que "[...] é fundamental que a educação prisional cumpra seu papel principal no processo educativo, promovendo condições para o desenvolvimento de potencialidades para a formação humana, o exercício da cidadania e a reintegração desse indivíduo, quando em liberdade".

Além das políticas públicas, o trabalho de Lourenço (2005) evidencia que as ações educacionais nos presídios são extremamente diferenciadas, porque sofrem no interior das instituições uma variação considerável, à medida que variam também a equipe dirigente e o corpo de funcionários. Para "captar" nuances do ambiente institucional e dos sujeitos que o compõe, examinou iniciativas escolares com quatro variáveis de análise: tempo, espaço, organização e práticas escolares.

Dois trabalhos dedicam-se a refletir sobre a docência: o de Amorim (2016), que investiga como o "professor do cárcere" constrói sua prática educativa, como vê o próprio papel neste contexto e, ainda, como está se apropriando da prisão como um espaço educativo. O resultado da pesquisa evidencia que os professores se esforçam para reconstruir suas formas de pensar, sentir e agir a educação; buscam reelaborar o contexto da prisão numa perspectiva contextualizada. Assim, o trabalho aponta para a necessidade de promover formação continuada específica para os educadores em prisões.

Sobre os professores Amorim (2016, p. 169) aponta ainda "[...] ser necessário que este educador discuta as condições concretas de existência de seus alunos, juntamente com os mesmos. Ao passo que estes possam questionar de onde vieram, como estão e o porquê de estarem naquela condição, para então poderem projetar-se num futuro".

Outro trabalho que faz uma reflexão sobre a docência é o de Menotti (2013). Investiga como os educadores em situação de privação de liberdade, conhecidos como "monitores presos", estabelecem significado para a experiência docente. Para eles, a prática docente tem relação com um sentimento de bem-estar gerado na escola, e esse fato contribui positivamente no processo de ensino-aprendizagem dos educandos.

A autora observou o trabalho de "monitores presos" na Penitenciária de Assis, SP, e concluiu como esses educadores leigos (re)significam a experiência docente no contexto prisional. Como aponta a docência é associada a questões subjetivas relativas a mediação do conhecimento, entre outros aspectos, mas também objetivas, como a remuneração e remição da pena. Segundo essa produção a docência na escola da prisão marca a vida desses educadores em diferentes aspectos, 
como a construção da identidade de professor, a mudança de concepções e de posturas, entre outros.

Mas, a extensa produção disponível sobre docência nos permite indicar que essa caracterização não se restringe ao exercício da docência no espaço-tempo da escola da prisão, antes compõe o produtivo discurso ou estereotipo de "ser professor", largamente difundido em nossa sociedade.

Os resultados apresentados em parte dos trabalhos ressaltam os aspectos positivos e até emancipadores da escolarização ou da educação em contraposição à instituição prisional, tida como negativa e disciplinadora, como já havia sido apontado sobre algumas produções analisadas por Zanetti e Catelli Jr. (2014).

Analisando os trabalhos, ou o mapa que com eles se pode produzir, pode-se admitir que a educação escolar ocupa lugar privilegiado na experiência dos sujeitos das pesquisas; aspecto que nos pareceu determinante para uma visão restrita presente em algumas produções, sobre o papel contraditório e questionável que a própria escola vem desempenhado na história da educação do país.

\section{CONSIDERAÇÕES FINAIS}

O estudo socializado neste texto teve como objetivo apresentar os resultados de um mapeamento de dissertações e teses que tomaram a educação escolar na prisão como objeto de estudo. Foram priorizadas as teses e dissertações disponíveis nas plataformas da Biblioteca Digital de Teses e Dissertações (BDTD-IBICT) e da Coordenação de Aperfeiçoamento de Pessoal do Ensino Superior (CAPES).

Percebe-se que os estudos sobre a temática são recentes e de certo modo escassos, pois dos 258 trabalhos localizados somente 12 tomaram a educação escolar no sistema prisional como objeto de estudo. Ainda assim a análise dos trabalhos proporcionou uma visão geral sobre as pesquisas, que tendem a refletir sobre a educação escolar na prisão como ferramenta de ressocialização, mas também de controle. Os trabalhos acessados "denunciam" aspectos como a falta de vagas, a necessidade de pensar as especificidades da Educação de Jovens e Adultos, sua dinâmica metodológica e didática, o espaço-tempo da escola na prisão, as elevadas taxas de reincidência inclusive entre os sujeitos que frequentaram a escola, o exercício da docência e as políticas públicas em curso, entre outros aspectos.

O mapa das produções, mesmo parcial, permitiu identificar aspectos considerados significativos para pensar a educação escolar prisional no país. Os discursos que circularam nas pesquisas analisadas afirmam a importância de pensar a educação na prisão de forma diferenciada, valorizando as especificidades ou particularidades deste espaço-tempo e a necessidade de políticas públicas e investimentos dirigidos para a educação. Mas evidencia-se, por parte dos sujeitos que colaboraram nas pesquisas, uma "crença" no papel ressocializador ou "redentor" da educação escolar. Entendimento que cerca a educação escolar em geral, para a qual tem-se atribuído o complexo papel 
de minimizar as desigualdades sociais instauradas no país, formar sujeitos capazes de atender a volatilidade do mercado de trabalho e auxiliar para que cada um exercite a cidadania.

Admitir que o espaço-tempo escolar compõe os sujeitos, como direito e como obrigação, significa considerar uma fabricação de subjetividades pelo seu produtivo fazer cotidiano. Porém, parte significativa da população não conseguiu ou consegue concluir a escolarização em nível médio, justificando a demanda e as chamadas a escolarização dessa franja da população, inserida na prisão.

Nesse sentido os trabalhos analisados apontam os limites e possibilidades da educação escolar no interior das prisões, suscitando inquietações e novos questionamentos.

Conclui-se que o tema permanece como algo a ser colocado na ordem do pensamento e problematizado na atualidade, assim como a sociedade e a educação escolar no país vêm sendo motivo de permanentes críticas e reflexões.

\section{REFERÊNCIAS}

1. ABREU, Janisley G. de. Os desafios da educação na prisão. Territorial. Caderno Eletrônico de Textos, Goiânia: Profissionais Instituições de Ensino, v. 6, n. 8, s.p, Març. 2016.

2. AMORIM, Karol O. de. Educar em prisões: um estudo na perspectiva das representações sociais. 2016. 194f. Dissertação (Mestrado em Educação) - UFMG, Belo Horizonte.

3. BARRETO, Maria das G. R. Relatório de pesquisa Projeto Político Pedagógico para educação em prisões: outras estratégias para outro sujeito de direito. 2017. 132f. Dissertação (Mestrado Profissional em Gestão e Tecnologias Aplicadas à Educação) - UNEB, Salvador.

4. $\quad$ BRASIL. Lei $n^{\circ}$ 9.394, de 20 de dezembro de 1996. Estabelece as Diretrizes e Bases da Educação Nacional. Brasília. 1996. Disponível em: http://www.planalto.gov.br/ccivil_03/Leis/L9394.htm. Constituição Federal da República Federativa do Brasil, de 5 de outubro de 1988. http://www.planalto.gov.br/ccivil_03/constituicao/constituição.htm.

6. _ _ Conselho Nacional de Educação. Parecer $\mathrm{n}^{\circ}$ 4, de 9 de março de 2010. Diretrizes Nacionais para a Oferta de Educação para Jovens e Adultos em Situação de Privação de Liberdade. $\quad 2010 . \quad$ Brasília, Disponível em: http://portal.mec.gov.br/index.php?option=com_docman\&view=download\&alias=4445-pceb00410\&category_slug=abril-2010-pdf\&Itemid=30192.

Lei n 7. 210, de 11 de julho de 1984. Lei de Execução Penal (LEP). Disponível em: ://www.planalto.gov.br/ccivil_03/LEIS/L7210.htm. 
Lei $n^{\circ}$ 12. 433, de 29 de junho de 2011. Altera a Lei no 7.210, de 11 de julho de 1984 (Lei de Execução Penal), para dispor sobre a remição de parte do tempo de execução da pena por estudo ou por trabalho. Disponível em: http://www.planalto.gov.br/ccivil_03/_ato20112014/2011/lei//12433.htm. Levantamento Nacional de Informações Penitenciárias (INFOPEN). 2016. Disponível em: http://www.justica.gov.br/news/ha-726-712-pessoas-presas-no-brasil/relatorio_2016_junho.pdf. Relatoria Nacional para o Direito Humano à Educação. Educação nas prisões brasileiras. São Paulo: Plataforma Dhesca Brasil, 2009. Disponível em: http://www.cmv-educare.com/wpcontent/uploads/2013/07/FINAL-relatorioeduca\%C3\%A7\%C3\%A3onasprisoesnov2009.pdf.

COYLE, Andrew. Administração penitenciária: uma abordagem de direitos humanos -Manual para Servidores Penitenciários. Londres: International Centre for Prison Studies, 2002.

12. FERREIRA, Norma S. de A. As pesquisas denominadas "Estado da arte". Educ. Soc., Campinas: CEDES; Campinas: UNICAMP, v. 15, n. 79, p. 257-272, ago. 2002. FOUCAULT, Michel. Microfísica do poder. Rio de Janeiro: Edições Graal, 2006. Michel. Outros espaços (1984). In: Ditos \& Escritos III. Estética: literatura e pintura, música e cinema. Organização e seleção de textos de Manuel Barros da Motta. Tradução Inês Autran Dourado Barbosa. 2. ed. Rio de Janeiro: Forense Universitária, 2001. p. 411-422. Michel. Vigiar e punir: história da violência nas prisões. 18. ed. Petrópolis: Vozes, 1987.

16. FRANCA, Francisca D. G. F. de. Processos educacionais no cárcere: um estudo sobre as representações sociais de jovens e adultos nas prisões. 2016. 144f. Dissertação (Mestrado em Educação) - UFRN, Natal.

17. FREIRE, Ana M. A. (Org.). Paulo Freire: pedagogia dos sonhos possíveis. São Paulo: Ed. Unesp, 2001.

18. GOMES, Priscila R. Tecendo fios nos espaços e tempos da escola na prisão. 2013. 212f. Tese (Doutorado em Educação) - UNICAMP, Campinas.

19. JULIÃO, Elionaldo F. Política pública de educação penitenciária: contribuição para o diagnóstico da experiência do Rio de Janeiro. 2003. 195f. Dissertação (Mestrado em Educação) - PUC-RJ, Rio de Janeiro. 

, Elionaldo F. A Ressocialização através do estudo e do trabalho no Sistema Penitenciário Brasileiro. 2009. In: ONOFRE, Elenice M. C.; JULIÃO, Elionaldo F. A educação na prisão como política pública: entre desafios e tarefas. Educação \& Realidade, Porto Alegre: UFRGS; Porto Alegre: Faed, v. 38, n. 1, p. 51-69, Jan./Mar. 2013.

LOURENÇO, Arlindo da $\mathrm{S}$. As regularidades e as singularidades dos processos educacionais no interior de duas instituições prisionais e suas repercussões na escolarização de prisioneiros: um contraponto à noção de sistema penitenciário? 2005. 220f. Dissertação (Mestrado em Educação: história, política, sociedade) - PUC-SP, São Paulo.

LUNA, Everardo C. Capítulos de direito penal. In: MIRABETE, Julio F.; FABBRINI, Renato. Execução Penal: comentários à lei no 7.210 de 11 de julho de 1984. 11 ed. São Paulo: Atlas, 2007. $874 p$.

MENOTTI, Camila C. O exercício da docência entre as grades: reflexões sobre a prática de educadores do sistema prisional do estado de São Paulo. 2013. 129f. Dissertação (Mestrado em Educação) - UFSCar, São Carlos.

ROSE, Nikolas. Inventando nossos eus. In: SILVA, Tomaz T. da (Org.). Nunca fomos humanos: nos rastros do sujeito. Trad. Tomaz Tadeu da Silva. Belo Horizonte: Autêntica, 2001. p. 137-204.

SANTOS, Ivanete A. da S. Direitos humanos e educação escolar prisional: um estudo de caso na Penitenciária Estadual de Cruzeiro do Oeste. 2017. 164f. Dissertação (Mestrado em Educação) UNIOESTE, Cascavel. Ciências Humanas) - PUC-GO, Goiânia.

27. SILVA, Mazukyevicz R. S. do N. O que pode a educação na prisão? 2011. 189f. Dissertação (Mestrado em Ciências Jurídicas) - UFPB, João Pessoa.

SORGE, Fabio J. A educação como forma de diminuição da reincidência e ressocialização dos detentos. 2010. 100f. Dissertação (Mestrado em Educação) - UNISAL, Americana.

VIDOLIN, Lucimara A. de M. Educação no sistema prisional: desafios, expectativas e perspectivas. 2017. 142f. Dissertação (Mestrado em Educação) - UTP, Curitiba.

ZANETTI, Maria A.; CATELLI JR., Roberto. Notas sobre a produção acadêmica acerca da educação em prisões - 2000/2012. In: FALCADE-PEREIRA, Ires A.; ASINELLI-LUZ, Araci (Orgs.). O espaço prisional: estudos, pesquisas e reflexões de práticas educativas. Curitiba: Appris, 2014. 
p. $19-58$.

\section{Ariane Martins Aragão}

Pedagoga, mestranda em Educação no PPGEdu/UFGD, na Linha História da Educação, Memória e Sociedade. Membro do Grupo de Estudos e Pesquisas em História da Educação, Memória e Sociedade (GEPHEMES).

\section{Rosemeire de Lourdes Monteiro Ziliani}

Doutora em Educação pela UFMS. Professora titular do Programa de Pós-Graduação em Educação, Faculdade de Educação da UFGD. Membro do Grupo de Estudos e Pesquisas em História da Educação, Memória e Sociedade (GEPHEMES) e Grupo de Estudos e Pesquisas nos Referenciais Foucaultianos (GEIARF).

\section{Como citar este documento:}

ARAGÃO, Ariane Martins; ZILIANI, Rosemeire de Lourdes Monteiro. Celas e salas: a recente produção acadêmica sobre educação escolar na prisão (2003-2017). Reflexão e Ação, Santa Cruz do Sul, v. 27, n. 2, apr. 2019. ISSN 1982-9949. Disponível em: <https://online.unisc.br/seer/index.php/reflex/article/view/12632>. Acesso em: doi:https://doi.org/10.17058/rea.v27i2.12632. 